\title{
450 años de la Facultad de Filosofía y Letras
}

\author{
Ambrosio Velasco Gómez
}

Hace 450 años inició la vida de nuestra Universidad con una oración solemne dentro de la cátedra de retórica impartida por Francisco Cervantes de Salazar. Si bien las cédulas de creación de la Real Universidad de México habían sido expedidas en 1551 por el príncipe Felipe II en nombre de su padre Carlos V, no es sino hasta dos años después cuando el proyecto de la Universidad se hace realidad.

Pero ¿đe qué proyecto se trata? ¿Cuál es su significación histórica y cultural?

Desde 1536, fray Juan de Zumárraga, primer obispo de México, pidió a Carlos V, emperador y rey de España, "mande en todo caso establecer y fundar en esta gran ciudad de México una universidad en la que se lean todas las facultades que se suelen leer en otras universidades", ${ }^{1}$ a fin de que se pudiera orientar la resolución de los problemas más graves de la evangelización, el maltrato y la explotación de los indios. Así pues en la carta de Zumárraga se avizoran ya las dos funciones principales de la Universidad de México: el cultivo del saber y la solución de los problemas más urgentes de la sociedad.

Afín a los propósitos de Zumárraga, en 1550 tres franciscanos encabezados por Juan de Villalpando subrayan que la Universidad debería de estar dedicada a la educación de los hijos de los indios y de los españoles. ${ }^{2}$ El proyecto era claro, la Universidad de México debería ser el crisol donde se forjara una cultura nacional propia, una segunda naturaleza que unificara a los naci-

1 "Séptimo capítulo de la instrucción de fray Juan de Zumárraga, 25 de noviembre de 1536”, en Sergio Méndez Arceo, La Real y Pontificia Universidad de México. México, UNAM, 1990, p. 106.

2 "Que vuestra alteza mande proveer en esta Nueva España una universidad de todas ciencias..., pues no puede tener firmeza ni estabilidad la cristiandad de estos naturales mientras no hubiese un estadio general en que ellos y los españoles se ejerciten en estudio de las letras" (ibid., p. 96). 
dos en estas tierras, más allá de su origen racial, español o indio. Ésta habría de ser la tarea esencial de la Universidad y de manera especial de los humanistas. Desde entonces la Universidad de México ha vinculado y comprometido su misión académica con la construcción de nuestra nación mexicana.

Pero el proyecto tuvo opositores desde el principio entre aquellos que veían en la Universidad una amenaza para el dominio sin límites de los conquistadores, encomenderos y de los prelados. Entre ellos el virrey de Mendoza expresó serias dudas sobre la viabilidad del proyecto de Zumárraga y apoyó más bien otro proyecto del Ayuntamiento de la ciudad de México orientado principalmente a la consolidación de la dominación de los hijos de españoles en la Nueva España, aunque ciertamente sin excluir formalmente a los indios. ${ }^{3}$ Por ello, al inicio del famoso diálogo de Francisco Cervantes de Salazar sobre la inauguración de los cursos en la Universidad, hace 450 años, expresaba la terrible duda: "En tierra donde la codicia impera ¿queda acaso algún lugar para la sabiduría?"

La pregunta expresa la disyuntiva que estuvo presente desde la conquista misma sobre nuestro destino: ¿ha de ser México una fuente de extracción de riquezas para el imperio mundial más grande que jamás hubiera existido o ha de ser una república con identidad cultural propia y autonomía política donde puedan convivir indios, españoles, criollos, mestizos y todo grupo étnico. ${ }^{4}$ Los catedráticos más eminentes de la naciente Universidad lucharon desde la academia por esta segunda alternativa y entre ellos fray Alonso de la Veracruz fue uno de los más destacados.

La Universidad surgió así como un proyecto humanista y renacentista. Su impulsor, fray Juan de Zumárraga era discípulo de Erasmo de Rotterdam ${ }^{5}$ y seguidor de la filosofía de Luis Vives. Para estos grandes pensadores del humanismo renacentista la convivencia de las diferentes culturas y la capacidad del diálogo intercultural es fundamental para el enriquecimiento y progreso de toda civilización. También Cervantes de Salazar fue un estudiosos y traductor de Luis Vives y como su maestro percibía que la codicia por el poder y la

${ }^{3}$ Cf. ibid., pp. 69-70. Véase también Armando Pavón Romero, "Fundación de la Real Universidad de México", en Tan lejos, tan cerca: a 450 años de la fundación de la Universidad de México. México, UnAM, 2001, pp. 20-21.

${ }^{4}$ Es importante señalar que esta disyuntiva se estaba discutiendo en la corte de Carlos V en 1551 en las juntas de Valladolid, donde se desarrolló la controversia entre Bartolomé de las Casas, defensor de los derechos de los indios y Ginés de Sepúlveda, abogado del imperio español. Sobre esta controversia véase Juan Álvarez Cienfuegos, La cuestión del indio: Bartolomé de las Casas frente a Ginés de Sepúlveda. Morelia, Red utopía y Filanjáfora Morelia, 2001, cap. VI.

${ }^{5}$ Sobre la influencia de Erasmo en Zumárraga, véase José M. Gallegos Rocaful, $E l$ pensamiento mexicano en los siglos XVI y XVII. México, UNAM, 1952, pp. 202-213. 
riqueza era el principal enemigo de la sabiduría y la fuente de la intolerancia respecto al cultivo de las humanidades. De ahí su duda sobre el futuro de la Universidad en una tierra donde la codicia impera.

En ese mismo diálogo de Cervantes de Salazar sobre el inicio de cursos, se describe a fray Alonso de la Veracruz como "el más eminente maestro en artes y en teología que haya en esta tierra y catedrático de prima de esta divina y sagrada facultad, sujeto de mucha y variada erudición, en quien compite la más alta virtud con la más exquisita y admirable doctrina" ${ }^{6}$

Esta misma descripción, podríamos hacerla hoy de nuestros profesores más admirados, especialmente los eméritos de nuestra Facultad: Antonio Caso, José Gaos, Eduardo Nicol, Wenceslao Roces, Edmundo O'Gorman, Juan M. Lope Blanch, Jorge A. Vivó, Juliana González, Margo Glantz, Luisa Josefina Hernández, Adolfo Sánchez Vázquez, Sergio Fernández, Leopoldo Zea, Carlos Solórzano y de muchos eméritos de otras dependencias que han ejercido su magisterio en esta Facultad: Luis Villoro, Ramón Xirau, Miguel León-Portilla, Fernando Salmerón, Alejandro Rossi, Ernesto de la Torre Villar, Beatriz de la Fuente, Elisa Vargaslugo, Rubén Bonifaz Nuño, Margit Frenk, Jorge Manrique, Alfredo López Austin, Elena Beristáin, Clementina Díaz y de Ovando, entre otros.

Podemos imaginarnos a todos ellos platicando en el Jardín Rosario Castellanos con los grandes maestros que ha tenido nuestra Facultad durante 450 años, a manera del maravilloso cuadro de "La Escuela de Atenas" de Rafael, donde antiguos y contemporáneos, filósofos y científicos, participan en un diálogo plural y universal. Este diálogo forma parte esencial de nuestra Facultad, de las humanidades y de la Universidad. Sin embargo, también me imagino la sorpresa de fray Alonso al ver que tres de nuestros eméritos son sapientísimas mujeres que discuten y discurren a la par con los profesores. Esto sin duda es un enorme progreso, pues en aquel entonces las mujeres estaban de facto excluidas de la Universidad y ahora son parte esencial de ella.

Fray Alonso de la Veracruz desarrolló una amplia obra magisterial y humanista. Desde antes de ser profesor en la Real Universidad de México, fray Alonso fundó en 1540, en Tiripitío, el primer colegio y la primera biblioteca de filosofía en América y cuatro años después estableció otros dos colegios en Tacámbaro y en Atotonilco. ${ }^{7}$ Ya como profesor de la Real Universidad de México publicó el primer libro de filosofía en toda América, Recognitio summularum (1554), con dos apéndices sobre lógica dialéctica: Tratado de

\footnotetext{
${ }^{6}$ Francisco Cervantes de Salazar, "La Universidad de México", en México en 1554. Tres diálogos latinos de Francisco Cervantes de Salazar. México, UNAM, 2001, p. 10.

${ }^{7}$ Cf. Mauricio Beuchot, La querella de la Conquista. Una polémica del siglo XVI. México, Siglo XxI, 1997, pp. 90-108.
} 
los tópicos dialécticos y Libro de los elencos sofísticos. ${ }^{8}$ La lógica dialéctica, a diferencia de la lógica analítica no era demostrativa, sino que sus conclusiones era probables y estaban orientadas a la argumentación de temas debatibles donde no cabe una ciencia demostrativa sino más bien opiniones razonables y persuasivas. Tal era el interés de fray Alonso en este tipo de lógica que en el mismo año de 1554 publicó también en México su Dialéctica resolutio. Como puede verse Alonso de la Veracruz estaba preocupado fundamentalmente por desarrollar una teoría y metodología para las controversias sobre los temas más debatidos de su tiempo, como era precisamente el de la legitimidad de la dominación española y los derechos de los pueblos indios.

Además de estas obras de lógica, Alonso de la Veracruz también publicó en México en 1557 Physica speculatio, considerada como la primera publicación de física en el Nuevo Mundo. ${ }^{9}$

Así pues, fray Alonso de la Veracruz no sólo fue el primer profesor y el primer escritor de filosofía en América, sino también el primer autor de un libro científico en el Nuevo Mundo. Con ello se expresa claramente el carácter unitario de la cultura humanista y la cultura científica del fundador de nuestra Facultad.

El amplio espectro de la actividad filosófica de fray Alonso de la Veracruz no significa de manera alguna dispersión. Por el contrario, su obra escrita y su magisterio universitario estaban encaminados a promover una formación amplia, crítica e integral de los estudiantes universitarios. Pero además podemos afirmar que su preocupación fundamental como "misionero de la filosofía”, como lo ha llamado Bernabé Navarro, se encaminó a la reflexión crítica sobre las injustas circunstancias en que vivían los pueblos indios bajo el dominio español. En este sentido, su magisterio y sus escritos sobre filosofía política y jurídica constituyen el punto central de su quehacer filosófico, y el crisol donde se integra su praxis política con su labor académica.

No es casualidad que la primera cátedra que impartió fray Alonso de la Veracruz hace cuatro siglos y medio fue "Sobre el dominio de los infieles y la guerra justa" en la cual cuestionó profundamente, desde el saber humanista más elaborado en el que se había formado en las universidades de Alcalá y

${ }^{8}$ Véase las traducciones con introducción y notas de Mauricio Beuchot sobre estos dos temas: fray Alonso de la Veracruz, Libro de los elencos sofísticos. México, UNAM, Instituto de Investigaciones Filológicas, 1989. Fray A. de la Veracruz, Tratado de los tópicos dialécticos. México, UNAM, Instituto de Investigaciones Filológicas, 1989.

9 Sobre las ideas científicas de este texto, véase Bernabé Navarro, "Astronomía y cosmología en la Physica speculatio de fray Alonso de la Veracruz", en B. Navarro, Filosofía y cultura novohispanas. México, UNAM, Instituto de Investigaciones Filosóficas, 1998 , pp. 85-93. 
de Salamanca, la legitimidad de la guerra de conquista y del dominio de la Corona española sobre los indios, defendiendo sus derechos, su libertad y su autonomía.

La cátedra o relección "Del dominio de los infieles" la impartió entre junio de 1553 y junio de 1554. Debido a su carácter radicalmente crítico al gobierno virreinal y a la explotación económica a través de la encomienda, esta obra fue censurada y no se permitió su publicación. De hecho este texto estuvo perdido durante varios siglos y se publicó por primera vez en 1968, en una edición bilingüe latín-inglés, traducida por E. J. Burrus. ${ }^{10}$ La misma suerte corrió la segunda relección sobre el diezmo que impartió fray Alonso en el año académico 1554-1555, pues en esta obra también condenaba la imposición de diezmos por parte de la Iglesia a los indígenas. ${ }^{11}$ Debido al fuerte cuestionamiento de fray Alonso al pago de diezmos por los indígenas y en general al poder de los obispos, especialmente el de la ciudad de México, Alonso de Montúfar, fray Alonso fue perseguido por la Inquisición. La cesura y la represión por parte del poder político y religioso lo obligó a dejar su cátedra universitaria y buscar defender el proyecto intelectual y político por el que luchaba en otros ámbitos, incluyendo la corte de Felipe II, a donde tuvo que comparecer en 1562 para defender su causa.

En su relección "sobre el dominio de los infieles y la guerra justa" fray Alonso recurre a la lógica dialéctica o dialógica, como forma de argumentación sobre tópicos controvertidos. Asimismo, se basa en una concepción republicana del poder político para refutar los argumentos a favor del dominio español en el Nuevo Mundo concedido por las bulas de Alejando VI, y al mismo tiempo defiende la legitimidad de los gobernantes indios sobre sus pueblos y de los naturales sobre sus tierras. De acuerdo a la Escuela de Salamanca y especialmente a Francisco Vitoria, su maestro, fray Alonso considera que todo poder político proviene directamente de la comunidad de ciudadanos sobre el que se ejerce dominio. ${ }^{12}$ Con esta tesis se echa por tierra las teorías del derecho divino de los reyes y en particular la potestad del papa

${ }^{10} \mathrm{Al}$ castellano se cuenta con traducción crítica de Roberto Heredia de las dudas I y II: fray A. de la Veracruz, De dominio infidelum et iusto bello, I y II. México, UNAM, Instituto de Investigaciones Filológicas, 2000; así como la traducción de Antonio Gómez Robledo de las dudas x y XI: Antonio Gómez Robledo, El magisterio filosófico y jurídico de Alonso de la Veracruz. México, Porrúa, 1984. El doctor Roberto Heredia está preparando una traducción crítica completa de las once dudas que constituyen al texto.

${ }^{11}$ Fray A. de la Veracruz, Sobre los diezmos. México, Organización de Agustinos de Latinoamérica, 1994. También existe una edición con la traducción completa de la obra, publicada por la Organización de Agustinos de Latinoamérica.

12 "Es necesario, pues, que si alguien tiene dominio justo, éste sea por voluntad de la comunidad", en fray A. de la Veracruz, De dominio infielium et iusto bello, p. 2. 
para conceder dominio político sobre el Nuevo Mundo al emperador español. Por otra parte, fray Alonso defiende la racionalidad plena de los indios y su civilización negando rotundamente que ellos sean bárbaros o "amentes", como pretendía Ginés de Sepúlveda. Por el contrario, "los habitantes del Nuevo Mundo no sólo no son niños o amentes sino que a su manera sobresalen del promedio... No eran por tanto tan niños o amentes como para ser incapaces de dominio". ${ }^{13}$ Con esta tesis en defensa de la racionalidad de los indios y sus comunidades políticas se refuta la justificación de intervención civilizatoria del dominio español. Así, para Alonso de la Veracruz el dominio político de los españoles era una usurpación y despojo, y la apropiación de las tierras de los indios un robo injustificable.

El magisterio filosófico de fray Alonso de la Veracruz, fundador de nuestra Facultad y primer maestro de filosofía en México y en América, nos recuerda continuamente el compromiso del saber científico y humanístico con la realización de los valores de justicia y libertad para las personas y pueblos de México, de Latinoamérica y del mundo. Sólo con un saber comprometido con estos valores de justicia y libertad es posible que la Universidad siga siendo el principal espacio de la sociedad civil donde se forje y renueve nuestra idea y proyecto de nación y sólo así se dé pleno sentido al lema de nuestra Universidad: "Por mi raza hablará el espíritu".

A 450 años de inicio de la enseñanza universitaria de la filosofía en México, es necesario reconocer y celebrar el magisterio y la obra filosófica del fundador de nuestra Facultad para recordar y renovar los compromisos académicos y sociales que como universitarios, como humanistas y particularmente como filósofos tenemos que desempeñar.

${ }^{13}$ Fray A. de la Veracruz, "Relectio de dominio infidelium", en Antonio Gómez Robledo, El magisterio filosófico y jurídico de Alonso de la Veracruz. México, Porrúa, 1984, duda X, pp. 15-16. 